\title{
Examining the use of evidence-based and social media supported tools in freely accessible physical activity intervention websites
}

\author{
Corneel Vandelanotte ${ }^{1 *}$, Morwenna Kirwan², Amanda Rebar ${ }^{1}$, Stephanie Alley ${ }^{1}$, Camille Short ${ }^{1}$, Luke Fallon ${ }^{1}$,
} Gavin Buzza', Stephanie Schoeppe ${ }^{1}$, Carol Maher ${ }^{3}$ and Mitch J Duncan'

\begin{abstract}
Background: It has been shown that physical activity is more likely to increase if web-based interventions apply evidence-based components (e.g. self-monitoring) and incorporate interactive social media applications (e.g. social networking), but it is unclear to what extent these are being utilized in the publicly available web-based physical activity interventions. The purpose of this study was to evaluate whether freely accessible websites delivering physical activity interventions use evidence-based behavior change techniques and provide social media applications.

Methods: In 2013, a systematic search strategy examined 750 websites. Data was extracted on a wide range of variables (e.g. self-monitoring, goal setting, and social media applications). To evaluate website quality a new tool, comprising three sub-scores (Behavioral Components, Interactivity and User Generated Content), was developed to assess implementation of behavior change techniques and social media applications. An overall website quality scored was obtained by summing the three sub-scores.

Results: Forty-six publicly available websites were included in the study. The use of self-monitoring (54.3\%), goal setting (41.3\%) and provision of feedback (46\%) was relatively low given the amount of evidence supporting these features. Whereas the presence of features allowing users to generate content (73.9\%), and social media components (Facebook (65.2\%), Twitter (47.8\%), YouTube (48.7\%), smartphone applications (34.8\%)) was relatively high considering their innovative and untested nature. Nearly all websites applied some behavioral and social media applications. The average Behavioral Components score was 3.45 ( \pm 2.53 ) out of 10. The average Interactivity score was $3.57( \pm 2.16)$ out of 10 . The average User Generated Content Score was $4.02( \pm 2.77)$ out of 10. The average overall website quality score was 11.04 $( \pm 6.92)$ out of 30 . Four websites $(8.7 \%)$ were classified as high quality, 12 websites $(26.1 \%)$ were classified as moderate quality, and 30 websites (65.2\%) were classified as low quality.

Conclusions: Despite large developments in Internet technology and growth in the knowledge of how to develop more effective web-based interventions, overall website quality was low and the majority of freely available physical activity websites lack the components associated with behavior change. However, the results show that website quality can be improved by taking a number of simple steps, and the presence of social media applications in most websites is encouraging.
\end{abstract}

Keywords: Physical activity, Web-based intervention, Freely accessible, Web 2.0, Social media, Behavior change, Interactivity, User generated content, Website quality, Online, Internet

\footnotetext{
*Correspondence: c.vandelanotte@cqu.edu.au

${ }^{1}$ Central Queensland University, Centre for Physical Activity Studies,

Rockhampton, QLD, Australia

Full list of author information is available at the end of the article
}

\section{Biomed Central}

(c) 2014 Vandelanotte et al.; licensee BioMed Central Ltd. This is an Open Access article distributed under the terms of the Creative Commons Attribution License (http://creativecommons.org/licenses/by/2.0), which permits unrestricted use, distribution, and reproduction in any medium, provided the original work is properly credited. The Creative Commons Public Domain Dedication waiver (http://creativecommons.org/publicdomain/zero/1.0/) applies to the data made available in this article, unless otherwise stated. 


\section{Introduction}

Population physical activity levels remain low and are a major public health concern in high-income countries. The burden and cost of inactivity to society are high due to being associated with non-communicable chronic diseases such as cardiovascular disease, some cancers, diabetes, osteoporosis, and obesity [1,2]. Given the magnitude of the problem, effective large-reach low-cost physical activity interventions are needed [1]. Implementing interventions through the Internet has substantial potential, as Internet access in most high-income countries is very high. For example, $79 \%$ of Australians have access to broadband Internet [3], and it is estimated that in 2015 there will be over 2.8 billion Internet users worldwide [4]. There are many advantages of using the Internet for health promotion and preventive medicine, including options for instantaneous interactivity, continued assessment and follow-up, individual tailoring, diverse delivery formats (e.g. (printable-) text, video, audio, e-mail or combination), anonymity, and high convenience $[5,6]$. Moreover, Internet interventions can reach respondents nearly anywhere at any time through desktops, laptops and mobile devices $[7,8]$.

However, achieving health behavior change through the Internet has proved to be considerably harder than anticipated [9]. While the potential of Internet technologies to change health behaviors has not yet been fully understood, web-based interventions still hold much promise. Recent reviews and meta-analyses in the field of physical activity show small and short-term effects in web-based interventions $[10,11]$. Long-term effects are lacking predominantly due to problems in attracting, engaging and retaining participants into web-based interventions $[12,13]$. However, much progress has been made and knowledge of what works and what doesn't in web-based interventions has grown tremendously in recent years $[13,14]$.

A number of strategies, frequently used in web-based behavior change interventions, are associated with positive health outcomes $[13,15]$. This includes strategies derived from behavior change theories such as the use of self-monitoring [16], goal setting [11,13], modeling [11], social support [14,16-18], and providing educational content [10]. But also the use of repeated contacts with participants [12,17], regularly updated websites [14], individually tailored feedback [11-13,17], e-mails [14,19], and alternative delivery modes (such as smartphone applications $[11,20]$ ) have shown to be effective components of web-based interventions. Furthermore, the level of 'interactivity' of behavior change websites itself has also shown to be essential for the effectiveness of web-based interventions $[13,21,22]$.

In this respect the development and implementation of social media applications, which can be defined as a group of online applications that allow for the creation and exchange of user-generated content [23], have vastly increased the interactivity of many websites in recent years. Several types of social media-based websites can be distinguished; examples are: collaborative projects (e.g., Wikipedia), blogs or microblogs (e.g., Wordpress and Twitter), content communities (e.g., YouTube), and social networking sites (e.g., Facebook) [23]. These tools are a part of what was, in 2004, termed Web 2.0: the utilisation of the World Wide Web as a platform where content is continuously modified by all users in a collaborative fashion [23]. Whilst the evidence regarding the effectiveness of social media applications for physical activity interventions is still emerging [24-28], there are several reasons illustrating why using social media applications for promoting behavior change might be important. Firstly, social media applications can reach very large audiences (e.g. Facebook has 1.1 billion users each month) and have high levels of user engagement and retention [29]. The highly dynamic and flexible nature of social media applications, with continuously changing content, is likely partly responsible for this high popularity and engagement [30]. Secondly, information can be delivered via existing contacts ('friends'), and this 'word-of-mouth' influence is more powerful than traditional social marketing strategies $[31,32]$. Thirdly, social media applications are characterized by user generated content and multidirectional communication flows in which users participate as both creators and consumers of web content [33]. This active engagement and content generation is more influential compared to websites that are passive or reactive in nature and which don't allow users to generate new content [33]. Finally, social media applications can link people to physical activity opportunities, highlight previously unknown preferences among individuals, enable role-modeling, allow normative comparisons, and provide instantaneous feedback and reinforcement [24].

In 2003 Doshi et al. [15] conducted an evaluation of freely available physical activity promotion websites and concluded that the use of theory-based strategies was low, and that websites provided little assessment, feedback or individually tailored assistance. Also in 2003, Evers et al. [6] assessed existing health behavior change websites and concluded that many did not include the basic requirements to achieve health behavior change. When Doshi et al. [15] and Evers et al. [6] conducted their analyses, the field of web-based interventions was relatively undeveloped compared to the current understanding. Over the subsequent years the knowledge of what website features and components are likely to change behavior and increase user engagement has been guided by a wealth of original studies, systematic reviews and metaanalyses $[11,12,14]$. Given the continued proliferation of un-evaluated physical activity promotion websites, the increased knowledge of effective web-based intervention 
components, and the large developments in Internet technology, it is timely to re-assess to what degree current physical activity promotion websites incorporate evidencebased behavior change techniques and innovative social media features. This will provide insight into the current implementation of useful intervention components and will inform future work surrounding the dissemination of effective web-based interventions.

The aim of this study was to evaluate to what extent freely available physical activity promotion websites apply techniques that have shown to be conducive for behavior change in intervention studies and to evaluate, for the first time, to what extent they incorporate social media applications which allow for enhanced user interactivity.

\section{Methods}

\section{Search strategy}

A search strategy was developed to identify freely available physical activity promotion websites on the Internet. Firstly, a number of relevant search terms were identified through discussion among the research team and through trial and error with popular search engines. Only the most relevant search terms, in relation to the results they generated, were retained for use (see Table 1). Secondly, a search engine was determined. Three highly used search engines (Google, Bing and Yahoo) were compared in relation of the results they returned to the selected

Table 1 Original and trend related search terms

\begin{tabular}{ll}
\hline Original search terms & Google trends related terms \\
\hline Exercise tracking & Fitness tracking \\
& Free exercise tracking \\
& Exercise software \\
Exercise tracker & Weight tracker \\
& Calorie exercise tracker \\
& Calorie tracker \\
Track my exercise & Nil. \\
Free exercise programs & Free weight programs \\
& Weight loss programs \\
Health tracking online & Online exercise program \\
Health tracking & Nil. \\
& Health tracking software \\
Free exercise websites & Environmental health tracking \\
Physical activity recording & Online health tracking \\
Exercise recording & Nil. \\
Walking tracker & Nil. \\
& Nil. \\
& gps walking tracker \\
& walking tracker app \\
& Walking distance tracker \\
\hline
\end{tabular}

search terms. As there was a very large overlap in the results of these search engines, it was decided to only use the most popular search engine at the time (Google) to conduct the data collection. Thirdly, to further increase the robustness of the search strategy, and ensure as many as possible relevant physical activity promotion websites were identified, the 'Google Trends' application was used to identify the most related search-terms for each originally entered search term. Google Trends (www.google.com/trends) is a public website of Google Inc. that indicates how often a particular search-term is entered relative to the total search-volume across various regions of the world. Google Trends identified the top three related search-terms for each original search-term, and these were added to the search strategy (see Table 1). This resulted in a total of 25 search terms. Fourthly, only the first 30 results for each search term were included, as beyond this point the search results became increasingly unrelated and irrelevant. This resulted in 750 web addresses that were processed in the next stage of the study. The search was conducted on 15 March 2013.

\section{Website selection}

The search results $(n=750$, see Additional file 1 for all web-addresses) were exported to an Excel spreadsheet where they were categorized into eight categories of different types of website (see Table 2 for summary of categorization) by two members of the research team (LF, GB) who accessed all the web-addresses to determine the correct categorization. Only those websites categorized as 'physical activity interventions' were included in the final data extraction process. An overview of the website selection process is provided in Figure 1; the web-addresses of included websites are provided in Figure 2.

\section{Data extraction}

Data extraction concerned two main areas: (1) website features that have shown to be conducive for behavior change in interventions studies aiming to increase physical activity [34,35], and (2) interactive features that allow users to generate and share information and that can be grouped as social media applications $[23,36]$. Tables 3 and 4 provide an overview of all website features for which data was extracted.

Data extraction was undertaken using purpose-designed data extraction forms which listed all the website features for which data needed to be extracted. The forms allowed coders to extract data from the selected websites in a convenient and consistent way. At the start of the data extraction, data for five websites was extracted independently by two members of the research team (LF, GB). This data was compared and the agreement between coders was very high (Cohen's Kappa Inter-coder reliability $(k)$ was 0.98 indicating nearly complete agreement). Data 
Table 2 Website categories and definitions

\begin{tabular}{lll}
\hline Website type & Definition & Number identified \\
\hline 1. Physical activity program & $\begin{array}{l}\text { Web-based program that has the intention to help people to become more active and/or } \\
\text { help people to live healthier, the goal being health behavior change }\end{array}$ & 204 \\
$\begin{array}{ll}\text { 2. Link to activity program } \\
\text { Website which only provides a link to a web-based physical activity promotion program } \\
\text { located on another website }\end{array}$ & 104 \\
$\begin{array}{ll}\text { 3. Smartphone application } \\
\text { 4. Health information }\end{array}$ & $\begin{array}{l}\text { A website either directly or indirectly linked to an application used on a smartphone } \\
\text { about physical activity }\end{array}$ & 116 \\
5. Article & Website that provides a media or scholarly article in relation to physical activity and health & 60 \\
6. Profile page & Website that provide profile pages of organisations (university and government) or people & 25 \\
7. Non physical activity program & With organisations that refer to physical activity and health & 59 \\
8. Other & Website that provides health program that is not related to physical activity & 35 \\
& $\begin{array}{l}\text { For example, websites not related to health, websites providing commercial software, } \\
\text { inactive websites (link does not work), commercial workplace health program, ... }\end{array}$ & 147 \\
\hline
\end{tabular}

extraction for the remaining websites was undertaken by one researcher (either LF or GB), with coders consulting each other for all cases where appropriate coding was ambiguous. When the coders could not come to an agreement they consulted other members of the research team (MD, MK, CV), and a decision was made based on consensus.

\section{Quality assessment}

Three sub-scores were developed to assess the overall quality of the websites that were assessed. The Behavioral Components score measured the presence of website components that have shown to be conducive for behavior change in interventions studies aiming to increase physical activity [34,35,37]. The Interactivity score measured the presence of website components that allowed users to interact with the website, as previous studies have shown that high levels of website interactivity are related to higher levels of behavior change [22]. The User Generated Content score measured the presence of website components that allowed users to generate new content on the website, either only accessible to a specific user (e.g. in a user profile), a user subgroup (e.g. 'friends') or all those that use the website. The ability for users to generate content is unique to social media applications [23], and represents a higher level of interactivity and potential for social support than websites that do not allow this.

Tables 3 and 4 indicate which website features were part of what sub-scores; when a feature was present on a website it scored ' 1 ', when it is absent it scored ' 0 '. Some website features were part of more than one of the subscores (e.g. as self-monitoring has shown to contribute to behavior change, provides website interactivity and/or allows users to generate new content simultaneously it was part of all three sub-scores). Overall website quality

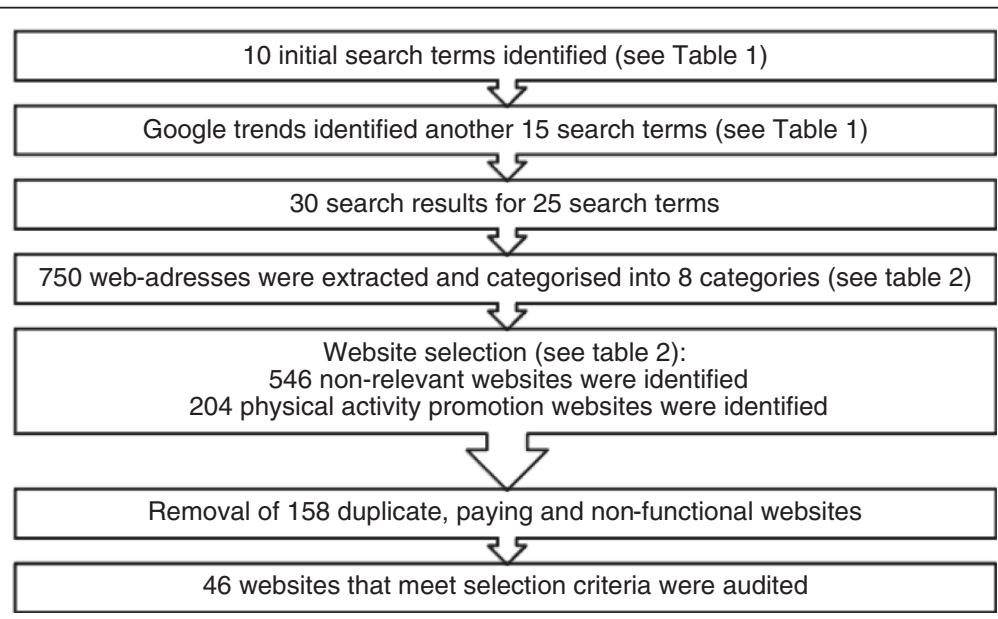

Figure 1 Flow chart. 


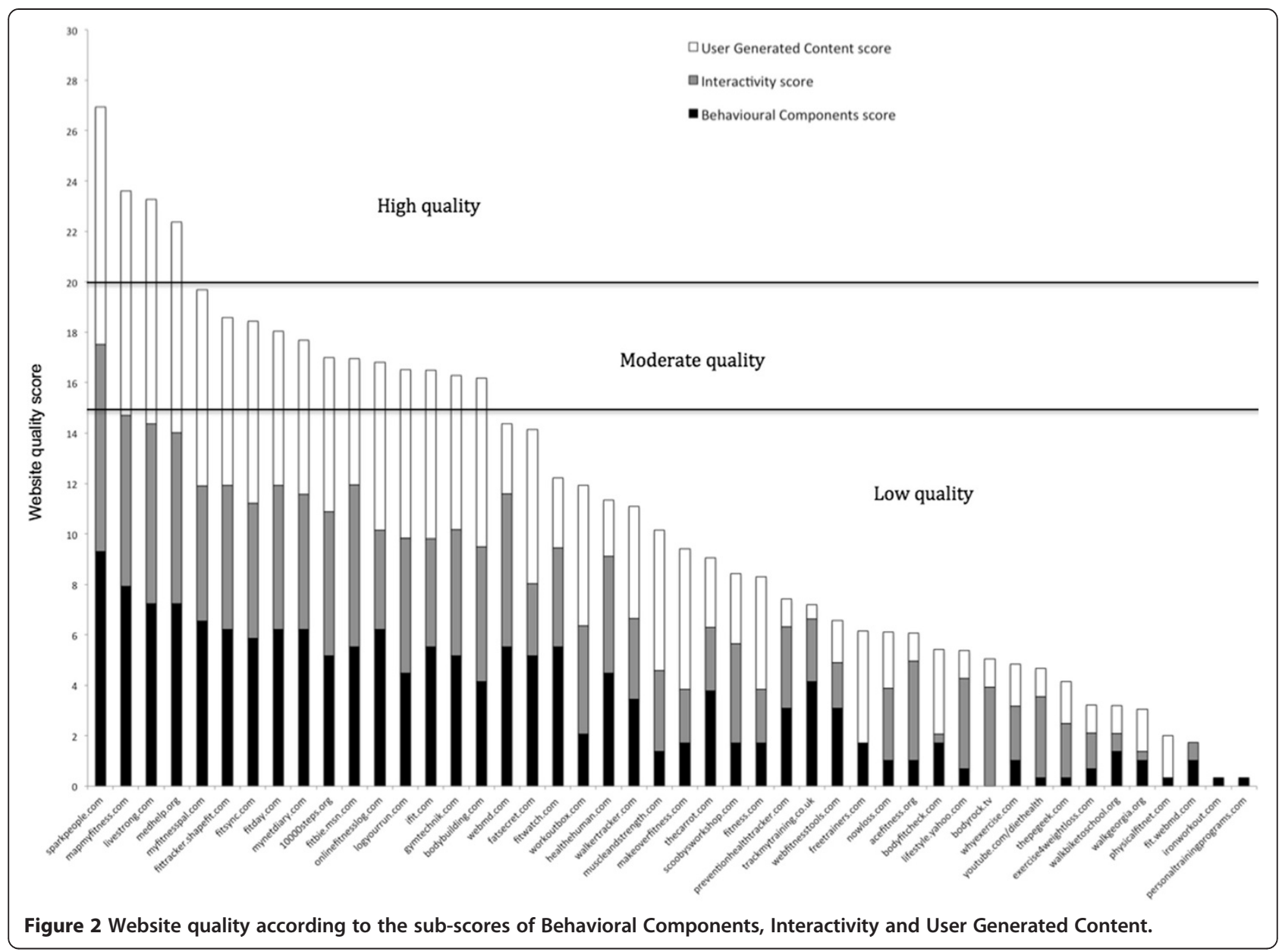

was obtained by summing the three sub-scores. However, the Behavioral Component, the Interactivity and the User Generated Content scores are made up of a different number of items: 27, 33 and 14 items respectively (see Tables 3 and 4). Therefore, to ensure that each sub-score weighted equally in the overall website quality score they were recalculated so that each sub-score would only contribute $1 / 3$ of the overall website quality score. To do this, each sub-score was divided by the total amount of items included in the sub-score and multiplied by 10. Thus, the minimum for each sub-score was 0 and the maximum score was 10 (e.g. for the Behavioral Components score: [(score obtained by website/27) * 10]). As such, when summing the three sub-scores, the overall website quality score ranged from 0 to 30 . In relation to this, items that were part of more than one sub-score (see Tables 3 and 4 for which items this applies) thus weighted more heavily on the overall website quality score. When items are part of more than one sub-score it means they influence several factors simultaneously (e.g. behavior change and interactivity) and are therefore considered more important than items that are part of one sub-score only. Websites that obtained
$66.7 \%$ or higher of the maximum score (being 30) were categorized as 'high quality websites'; those obtaining a score between $50 \%$ and $66.6 \%$ of the maximum score were categorized 'moderate quality websites'; and those obtaining a score lower than $50 \%$ of the maximum score were categorized as 'low quality websites' [38].

\section{Analyses}

Basic descriptive statistics were used to report on the prevalence of the different website features across all categories.

\section{Results}

Of the 750 websites that were extracted through the Google search engine, 204 were initially identified as physical activity promotion websites (see Figure 1). However, upon closer inspection 158 of those were discarded based on either being a duplicate, non-functional or a commercial website that required payment for access to the website. As such, 46 websites remained and were subjected to the data extraction method. The following sections only relate to this final sample of websites. 
Table 3 Behavior change related website features

Targeting other health behaviors (number):

- Targeted only physical activity

- Targeted one other behavior

- Targeted two other behaviors

- Targeted three or more other behaviors

Targeting other health behaviors (what):

- Weight loss

- Diet or calories

- Diabetes

- High blood pressure

- Cardio-vascular disease

- Other diseases

Tracking tools related to other behaviors:

- Weight

- Diet

- Calories

- Body mass index

- Mood

- Sleep

- Stress

- Tobacco use

- Alcohol use, sitting time

Educational information:

- Provided general physical activity information

- Provided information on the benefits of physical activity

- Provided information on barriers to being active

- Provided references for the information provided

Physical activity tracking:

- Provides any kind of physical activity assessment

- Provides a once off assessment, to assess current situation

- Provides ongoing self-monitoring of physical activity

- Allowed participants to set activity goals

Method used for physical activity tracking:

- Online physical activity log

- iPhone accelerometer

- GPS

- Heart rate monitor

- Pedometer

- Accelerometer (e.g. Fitbit, Jawbone UP)

- Survey

- Uses one method to track physical activity

- Uses two methods to track physical activity 
Table 3 Behavior change related website features (Continued)

\begin{tabular}{|c|c|c|c|}
\hline \multicolumn{4}{|l|}{ Type of physical activity tracking: } \\
\hline - Time based (e.g. minutes) & 23 & 50 & a \\
\hline - Activity based (e.g. walking) & 22 & 47.8 & a \\
\hline - Intensity based (e.g. vigorous) & 21 & 45.7 & a \\
\hline - Distance based (e.g. kilometres) & 18 & 39.1 & a \\
\hline - Calorie based (e.g. Kcal) & 13 & 28.9 & a \\
\hline - Other (e.g. steps, heart rate) & 4 & 8.8 & a \\
\hline - One or two types of physical activity tracking & 2 & 4.3 & \\
\hline - Three or four types of physical activity tracking & 9 & 19.5 & \\
\hline - Five types of physical activity tracking & 13 & 28.3 & \\
\hline \multicolumn{4}{|l|}{ Provision of feedback: } \\
\hline - No form of feedback is being provided & 25 & 54.3 & \\
\hline - Generic text-based feedback & 23 & 50 & $a, b$ \\
\hline - Generic image or graph based feedback & 22 & 47.8 & $a, b$ \\
\hline - Generic voice, video or avatar based feedback & 0 & 0 & $a, b$ \\
\hline - Targeted or tailored text-based feedback & 1 & 2.2 & $a, b$ \\
\hline - Targeted or tailored image or graph based feedback & 2 & 4.3 & $a, b$ \\
\hline - Targeted or tailored voice, video or avatar based feedback & 0 & 0 & $a, b$ \\
\hline
\end{tabular}

Note. Sub-score: $a=$ part of the Behavioral Components Score; $b=$ part of the Interactivity Score; $c=$ part of the User Generated Content Score.

\section{Features related to behavior change}

Few of the assessed websites (10.9\%) focused solely on physical activity; more than half (52.2\%) focused on two additional behaviors (see Table 3). In addition to physical activity, diet and weight loss were targeted in $80.4 \%$ and $82.6 \%$ of the websites respectively. Many websites also provided specific tools to self-monitor or track these additional behaviors, with the two most popular alternative tools being a weight tracker (available on $56.5 \%$ of all websites) and a dietary tracking tool (available on $41.3 \%$ of all websites).

The majority of assessed websites provided educational information about physical activity (76.1\%), which included information on the benefits of being active in about half of the websites (47.8\%). However, few websites provided information on how to overcome barriers to physical activity $(6.5 \%)$ or provided information regarding where this educational information was sourced (6.5\%).

Just over half of all websites (54.3\%) provided tools for ongoing self-monitoring of physical activity, whereas only 41.3\% of websites allowed participants to set activity goals. Among those websites that allowed ongoing selfmonitoring, half (26.1\% of all websites) provided only one option for participants to track their activity level, whereas the remaining websites (24\% of all websites) provided two or more options. The most popular tracking tool was a physical activity log, available in nearly all websites that provided self-monitoring (50\% of all websites), followed by self-monitoring using an inbuilt smartphone accelerometer (23.9\% of all websites). Almost all websites that provided self-monitoring offered to track physical activity using multiple activity indicators, such as time-, distance-, intensity- and calorie-based tracking methods.

More than half of all websites (54\%) did not provide any feedback to participants about their physical activity behavior, and of those that did the majority provided generic text-based (50\%) or image/graph-based (47.8\%) feedback, with only a very small number of websites offering targeted or tailored feedback (text-based: one website; image/graph-based: two websites). None of the websites offered feedback using voice (e.g. podcast), video or avatars.

\section{Social media applications}

More than $70 \%$ of the websites offered options for users to generate content; $45.8 \%$ off all websites had five or more options for users to share content (see Table 4). The most popular options for content sharing were social media status updates (58.7\%), discussion forums (50\%), sharing success stories (50\%), uploading photos (47.8\%), blogs (43.5\%) and the option to make comments (39.1\%).

Gamification features (website components that have game like features) were less frequently used; less than one quarter of websites (23.9\%) had some gamification features. Though most websites that did use gamification features had more than one such feature available for users. Most popular gamification features were in relation to the creating and participating in challenges as individuals or teams. 
Table 4 Social media features

\begin{tabular}{|c|c|c|c|}
\hline Website feature & Number $(n=46)$ & Percent & Sub-score \\
\hline \multicolumn{4}{|l|}{ Types of user generated content: } \\
\hline - Sharing status updates & 27 & 58.7 & c \\
\hline - Discussion forum & 23 & 50 & c \\
\hline - Allowing personal user interactions & 23 & 50 & c \\
\hline - Sharing success stories or testimonials & 23 & 50 & $a, c$ \\
\hline - Uploading photos or images & 22 & 47.8 & c \\
\hline - Providing blogs & 20 & 43.5 & c \\
\hline - Adding comments & 18 & 39.1 & c \\
\hline - Share activity levels & 10 & 21.7 & c \\
\hline - Invite new users to the site & 9 & 19.6 & $a, c$ \\
\hline - Google Map mash-ups & 8 & 17.4 & c \\
\hline - No options for users to generate content & 12 & 26.1 & \\
\hline - One or two options for users to generate content & 9 & 19.6 & \\
\hline - Three to four options for users to generate content & 4 & 8.7 & \\
\hline - Five to six options for users to generate content & 6 & 13.1 & \\
\hline - Seven to eight options for users to generate content & 9 & 19.6 & \\
\hline - Nine to ten options for users to generate content & 6 & 13.1 & \\
\hline \multicolumn{4}{|l|}{ Gamification features: } \\
\hline - Participation in challenges & 9 & 19.6 & $b$ \\
\hline - Creation of challenges & 8 & 17.4 & $b, c$ \\
\hline - Creation of activity teams & 5 & 10.9 & $b, c$ \\
\hline - Ability to earn points & 4 & 8.7 & a \\
\hline - Leader board rankings & 4 & 8.7 & a \\
\hline - Ability to earn trophies & 3 & 6.5 & a \\
\hline - Ability to earn badges & 2 & 4.3 & a \\
\hline - Ability to earn medals & 2 & 4.3 & a \\
\hline - No gamification features available & 35 & 76.1 & \\
\hline - One or two gamification features available & 6 & 13.1 & \\
\hline - Three or more gamification features available & 5 & 10.9 & \\
\hline \multicolumn{4}{|l|}{ Sharing of information with other websites through widgets: } \\
\hline - No options to share through widgets & 13 & 28.3 & \\
\hline - Facebook widget & 32 & 69.6 & $b$ \\
\hline - Twitter widget & 27 & 58.7 & $b$ \\
\hline - Pintrest widget & 16 & 34.8 & $b$ \\
\hline - Google widget & 15 & 32.6 & $b$ \\
\hline - e-mail widget & 15 & 32.6 & $b$ \\
\hline - Tumblr widget & 7 & 15.2 & $b$ \\
\hline - Linkedin widget & 6 & 13.1 & $b$ \\
\hline - Flicker widget & 6 & 13.1 & $b$ \\
\hline - Other ( $>5$ for each): Research gate, Myspace, Blogger & 22 & 47.8 & \\
\hline \multicolumn{4}{|l|}{ Has a presence on Facebook: } \\
\hline - No Facebook presence & 16 & 34.8 & \\
\hline - Low Facebook usage (<1 update/week) & 3 & 6.5 & $b$ \\
\hline
\end{tabular}


Table 4 Social media features (Continued)

\begin{tabular}{|c|c|c|c|}
\hline - Medium Facebook usage (1 to 6 updates/week) & 10 & 21.7 & $b$ \\
\hline - High Facebook usage ( $\geq 7$ updates/week) & 17 & 37 & $b$ \\
\hline \multicolumn{4}{|l|}{ Has a Twitter feed: } \\
\hline - No Twitter feed & 24 & 52.2 & \\
\hline - Low Twitter usage (<1 update/week) & 3 & 6.5 & $b$ \\
\hline - Medium Twitter usage (1 to 6 updates/week) & 4 & 8.7 & $b$ \\
\hline - High Twitter usage ( $\geq 7$ updates/week) & 15 & 32.6 & $b$ \\
\hline \multicolumn{4}{|l|}{ Has a YouTube channel: } \\
\hline - No YouTube channel & 24 & 52.2 & $b$ \\
\hline - Has between 0 and 10 videos on channel & 7 & 15.2 & \\
\hline - Has between 11 and 30 videos on channel & 4 & 8.7 & \\
\hline - Has more then 30 videos on channel & 11 & 23.9 & \\
\hline \multicolumn{4}{|l|}{ Has a smartphone application } \\
\hline - No smartphone application & 30 & 65.2 & \\
\hline - Has iOS (Apple) application & 16 & 34.8 & $\mathrm{~b}$ \\
\hline - Has Android (Google) application & 6 & 13.1 & $\mathrm{~b}$ \\
\hline - Has a free smartphone app & 11 & 23.9 & \\
\hline - Has a commercial smartphone app (range: \$1.99- \$4.99) & 5 & 10.9 & \\
\hline \multicolumn{4}{|l|}{ Other social media features: } \\
\hline - Has a 'Wiki' & 1 & 2.2 & $b, c$ \\
\hline - Has an 'RSS feed' & 13 & 28.3 & $b$ \\
\hline - Has ability to log in via social media integration & 14 & 30.4 & $b$ \\
\hline
\end{tabular}

Note. Sub-score: $\mathrm{a}=$ part of the Behavioral Components Score; $\mathrm{b}=$ part of the Interactivity Score; $\mathrm{c}=$ part of the User Generated Content Score.

Most websites (71.7\%) provided options to share content of their website with other websites through widgets, with Facebook (69.6\%) and Twitter (58.7\%) being the most popular websites content could be shared to. All the websites that embedded widgets provided more than one option for users to share content with external websites. Many websites also had their own Facebook page (65.2\%) or a Twitter Feed $(47.8 \%)$ and the majority of those were characterized by high usage (updates are provided at least once a day), as the page administrator provided frequent page updates or 'tweeted' regularly. Nearly a third of websites $(30.4 \%)$ also allowed users to log into their website using their password and username from another website, such as Facebook; this social media integration makes it more convenient for people to use their website.

Approximately half of websites (47.8\%) had a 'YouTube' channel, the majority of which had more than 30 videos available for users to watch. Just over one third of the websites (34.8\%) had their own smartphone application; all of which had an application supported by Apple's iOS platform, while only six websites offered an application supported by Google's Android platform. Two thirds of the smartphone applications were offered for free to users, whereas the other third required a fee ranging from $\$ 1.99$ to $\$ 4.99$.

\section{Website quality}

The average Behavioral Components score was 3.45 $( \pm 2.53)$ out of 10 ; four websites $(8.7 \%)$ were classified as high (score was 6.67 or higher) on this sub-score, 13 websites $(28.2 \%)$ were classified as moderate (score was between 5 and 6.66) and 29 websites (63.0\%) were classified as low (score was lower than 5). The average Interactivity score was $3.57( \pm 2.16)$ out of 10 ; four websites $(8.7 \%)$ were classified as high on this sub-score, 11 websites (23.9\%) were classified as moderate and 31 websites (67.4\%) were classified as low. The average User Generated Content score was $4.02( \pm 2.77)$ out of 10 ; 11 websites $(23.9 \%)$ were classified as high on this sub-score, nine websites (19.5\%) were classified as moderate and 26 websites (56.5\%) were classified as low. The average overall website quality score was $11.04( \pm 6.92)$ out of 30 (see Figure 2); four websites (8.7\%) were classified as high quality, 12 websites (26.1\%) were classified as moderate quality, and 30 websites (65.2\%) were classified as low quality.

\section{Discussion}

This study evaluated freely available physical activity promotion websites to inform future work surrounding the dissemination of web-based interventions. The findings from this study may be useful for consumers, researchers, 
health care providers and website developers. The outcomes of this study illustrate that there are many free physical activity websites available on the Internet which use a wide variety of behavior change and social media components; however website quality was predominantly low aside from a small number of websites with good overall quality.

Only two of the 24 websites (www.ifit.com and www. webMD.com) reviewed by Doshi et al. [15] were among the 46 websites reviewed in this study and have continued to be available over the 10-year time gap between reviews. Although using a different assessment tool, the quality of one of these websites seemed to have improved over time (both were categorised as having low quality in the Doshi et al. [15] study; www.ifit.com was classified as having moderate quality in this study). The small overlap between both studies illustrates the dynamic and rapidly changing nature of the Internet. Despite this, many of the outcomes of Doshi et al. [15] are to a large extent comparable with the current study. Doshi et al. [15] also found that most websites provided sufficient educational information, but that the use of evidence-based strategies was low, and that websites provided little individually tailored assistance. Similarly, Doshi et al. [15] also found that a handful of websites out-performed the majority, and that there is substantial variation in physical activity websites with regard to behavior change offerings.

Similar studies in related fields found comparable outcomes demonstrating low website quality and capacity to change behavior. Evers et al. [6] who evaluated websites for a range of health behaviors reported low implementation of web-based components that provide tailored feedback, theory and interactivity. Bonar-Kidd et al. [39] who focussed on physical activity websites for cancer prevention indicated that only 4 (22\%) of the 17 websites they surveyed were of high quality and concluded that information seekers are at risk for disease and injury. Shanar et al. [40] assessed websites focussing on diet and nutrition and indicated that $54 \%$ of websites had low quality and that there is great concern about the accuracy of the information being disseminated. Gorczynski et al., [41] who examined the quality of physical activity, exercise and sport information for people with schizophrenia, reported that most websites (59\%) they examined did not provide information supported by any physical activity guidelines and that few websites (29\%) discuss cognitive or behavioral aspects that could promote physical activity participation. This finding is in line with a study reporting that websites for breast cancer prevention lack behavior change components that impede on users' motivations to protect themselves against breast cancer [42]. The present study builds on these previous reviews by also examining social media components as part of the overall assessment of website quality, and as it is the first study to do so it is not possible to compare outcomes with other studies on this specific dimension of website quality.

The majority (89.1\%) of included websites addressed multiple health behaviors, and allowed tracking of these behaviors simultaneously; this was also observed in the study by Evers et al. [6] that reported that $78 \%$ of websites addressed multiple behaviors. There is some evidence indicating that interventions that address multiple health behaviors simultaneously are equally or more effective compared to those who address behaviors sequentially $[43,44]$, as such it may be a positive observation to see so many websites addressing multiple health behaviors.

Despite the importance of established behavior change techniques (self-monitoring [17], goal setting [13], and providing feedback [11]), and the ability to easily implement them through the Internet, only about half of the included websites provided these features. Websites lacking such features are as such seriously limiting the potential for behavior change. The overall lack of targeted or tailored feedback was especially concerning, as there is considerable evidence supporting the effectiveness of personally relevant feedback [45]. While it is not difficult to provide targeted or tailored feedback from a technical point of view, developing targeted and tailored content in itself is complex and requires a deep understanding of the target behavior, as well as a good knowledge of health behavior change principles and theories. It may be that developers and providers in the field lack this expertise and therefore refrain from providing targeted and tailored feedback.

There is substantial evidence that web-based interventions are increasingly more effective if they incorporate more behavior change techniques [11,37]. Therefore it is positive to observe in Figure 2 that, despite the lack of basic behavior change tools in many websites, the majority of websites deployed a range of tactics to persuade users to become more active. As such, it was also encouraging to observe that nearly all websites incorporated features that allowed users to generate new content themselves. In fact, the User Generated Content sub-score was higher than the other sub-scores, and there were more websites with a high score $(n=11)$ on this scale when compared to the other scales. Webb et al. [11] reported that the effectiveness of web-based interventions is enhanced when additional methods of communicating with participants are used. Therefore the large and active presence of the included websites on platforms such as Facebook, Twitter and YouTube, as well as the use of social media integration and smartphone applications are positive trends that should be encouraged. Developers and health promoters should nevertheless be aware that user demographics of popular social media platforms are dynamic and continuously changing, as is the mode on how the Internet is accessed with a rapid increase in the use of 
mobile devices. Furthermore, the proliferation and change in web-applications is driven by a continuous interaction with user demand/experience/feedback and by technological (hard- and software) innovations. In order to be effective and reach intended audiences, web-based interventions will continuously need to adapt to these changes.

There are several study limitations. First, the Internet is a dynamic environment; conducting the web-search on another day may have resulted in different search outcomes. As such, the outcomes of this study provide only a momentary snapshot. Longitudinal reviews are needed to determine if websites are improving and how web-based physical activity promotion is changing over time. Second, the website quality outcomes obtained in this study are not linked to studies assessing effectiveness and maintenance of behavior change. A website with a higher quality score may not necessarily be more effective in increasing physical activity when compared to a website with a lower quality score. It may be that some websites included fewer website components, but implement them particularly well. Similarly, this study did not assess how quality was related to usage as some websites that scored poorly may have a large user-base. Further, the actual content of the websites was not assessed for correctness. In line with this, the videos provided by websites having a YouTube channel may have provided important behavioural or educational information over less relevant promotional information. As video content was not assessed, this is another limitation of the website quality scoring system. Third, this study only assessed free and publicly available websites. It may be that commercial websites with paying consumers have higher quality with regards to behavior change components and use of web social media applications. Finally, this study only examined English websites; website quality of non-English websites may differ. This study also has strengths. An innovative assessment tool that is in tune with how the Internet is being used today was developed. It assessed both new social media applications and established behavior change techniques. To our knowledge this is the first study to review the use of social media components in freely available physical activity websites. Further, the inter-coder reliability for included websites was very high, which provides confidence in the results presented.

\section{Conclusion}

Ten years ago Evers et al. [6] concluded that the Internet was in the early phases of development with regards to health behavior change, as most programs readily available to consumers did not provide the basic components necessary for health behavior change. Despite large developments in Internet technology and large growth in the knowledge of how to design and implement web-based physical activity interventions [13,14], the majority of freely available physical activity websites still appear to be lacking the components and features likely to produce behavior change. However, the results of this study illustrate that website quality can be improved by taking a number of simple steps, and the presence of features that allow users to generate content in most websites is encouraging.

\section{Additional file}

Additional file 1: Full list of web-addresses $(n=750)$ retrieved as a result of the search strategy.

\section{Competing interests}

The authors declare that they have no competing interests.

\section{Authors' contributions}

CV was involved in study conceptualization, and writing the manuscript; MK was involved in study conceptualization and guiding the data collection; MJD was involved in study conceptualization and study coordination. CM, CV, MK, MJD and LF developed the data extraction tool; LF and GB extracted the data; AR and SA developed the website quality tool; CS and SS conducted the data analyses. All authors read, revised and approved the final manuscript.

\section{Author details}

${ }^{1}$ Central Queensland University, Centre for Physical Activity Studies, Rockhampton, QLD, Australia. ${ }^{2}$ University of Western Sydney, School of Science and Health, Sydney, NSW, Australia. ${ }^{3}$ University of South Australia, School of Health Sciences, Health and Use of Time Group, Adelaide, South Australia, Australia.

Received: 23 November 2013 Accepted: 8 August 2014

Published: 17 August 2014

\section{References}

1. Lee IM, Shiroma EJ, Lobelo F, Puska P, Blair SN, Katzmarzyk PT, Lancet Physical Activity Series Working Group: Effect of physical inactivity on major non-communicable diseases worldwide: an analysis of burden of disease and life expectancy. Lancet 2012, 380:219-229.

2. Warburton DER, Nic.ol CW, Bredin SSD: Health benefits of physical activity: the evidence. Can Med Assoc J 2006, 174:801-809.

3. Australian Bureau of Statistics: Houshold use of Information Technology 2010-2011 No. 8146.0. Australian Bureau of Statistics: Canberra; 2011.

4. Computer Industry Almanac: Internet Users by Country: Historical Estimates and Forecast for the Number of all Internet Users, Weekly Internet Users and Broadband Subscribers for Over 57 Countries. Illinois, USA: Computer Industry Almanac Inc; 2012.

5. Atkinson NL, Gold RS: The promise and challenge of eHealth interventions. Am J Health Beh 2002, 26:494-503.

6. Evers KE, Prochaska JM, Prochaska JO, Prochaska JM: Strengths and weaknesses of health behavior change programs on the Internet. $J$ Health Psychol 2003, 8:63-70.

7. Ritterband LM, Thorndike FP, Cox DJ, Kovatchev BP, Gonder-Frederick LA: A behavior change model for internet interventions. Ann Beh Med 2009, 38:18-27.

8. Wantland DJ, Portillo CJ, Holzemer WL, Slaughter R, McGhee EM: The effectiveness of Web-based vs. non-Web-based interventions: a meta-analysis of behavioral change outcomes. J Med Internet Res 2004, 6(4):e40.

9. Marshall AL, Leslie ER, Bauman AE, Marcus BH, Owen N: Print versus website physical activity programs - a randomized trial. Am J Prev Med 2003, 25:88-94.

10. Davies CA, Spence JC, Vandelanotte C, Caperchione CM, Mummery WK: Meta-analysis of internet-delivered interventions to increase physical activity levels. Int J Beh Nutr Phys Activ 2012, 9(1):52.

11. Webb TL, Joseph J, Yardley L, Michie S: Using the Internet to promote health behavior change: A systematic review and meta-analysis of the 
impact of theoretical basis, use of behavior change techniques, and mode of delivery on efficacy. J Med Internet Res 2010, 12:e4.

12. Vandelanotte C, Spathonis KM, Eakin EG, Owen N: Website-delivered physical activity interventions. A review of the literature. Am J Prev Med 2007, 33:54-64.

13. Kohl LFM, Crutzen R, De Vries NK: Online prevention aimed at lifestyle behaviors: a systematic review of reviews. J Med Internet Res 2013, 15(7):e146.

14. Brouwer W, Kroeze W, Crutzen R, De Nooijer J, De Vries NK, Brug J, Oenema A: Which intervention characteristics are related to more exposure to internet-delivered healthy lifestyle promotion interventions? A systematic review. J Med Internet Res 2011, 13:e2.

15. Doshi A, Patrick K, Sallis JF, Calfas K: Evaluation of physical activity Web sites for use of behavior change theories. Ann Beh Med 2003, 25:105-111.

16. Tate DF, Jackvony EH, Wing RR: Effects of Internet behavioral counseling on weight loss in adults at risk for type 2 diabetes - A randomized trial. JAMA 2003, 289:1833-1836.

17. Morrison LG, Yardley L, Powell J, Michie S: What design features are used in effective e-health interventions? A review using techniques from Critical Interpretive Synthesis. Telemed J e-Health 2012, 18:137-144.

18. Winett RA, Anderson ES, Wojcik JR, Winett SG, Bowden T: Guide to health: nutrition and physical activity outcomes of a group randomised trial of an internet-based intervention in churches. Ann Beh Med 2007, 33:251-261.

19. Plotnikoff RC, McCargar $L$, Wilson PM, Loucaides CA: Efficacy of an e-mail intervention for the promotion of physical activity and nutrition behavior in the workplace context. Am J Health Promot 2005, 19:422-429.

20. Kirwan M, Duncan MJ, Vandelanotte C, Mummery WK: Using smartphone technology to monitor physical activity in the 10,000 Steps program: a matched case-control trial. J Med Internet Res 2012, 14:e55.

21. Leslie E, Marshall AL, Owen N, Bauman A: Engagement and retention of participants in a physical activity website. Prev Med 2005, 40:54-59.

22. Hurling R, Fairley BW, Dias MB: Internet-based exercise intervention systems: Are more interactive designs better? Psychol Health 2006, 21:757-772.

23. Kaplan AM, Haenlein M: Users of the world, unite! The challenges and opportunities of social media. Buisiness Horzions 2010, 53:59-68.

24. Rovniak LS, Sallis JF, Kraschnewski JL, Sciamanna CN, Kiser EJ, Ray CA, Chinchilli VM, Ding D, Matthews SA, Bopp M, George DR, Hovell MF: Engineering online and in-person social networks to sustain physical activity: application of a conceptual model. BMC Pub Health 2013, 13:753.

25. Kolt GS, Rosenkranz RR, Savage TN, Maeder AJ, Vandelanotte C, Duncan MJ, Caperchione CM, Taque R, Hooker C, Mummery WK: WALK 2.0 - Using Web 2.0 applications to promote health-related physical activity: A randomised controlled trial protocol. BMC Pub Health 2013, 13:436.

26. Cavallo DN, Tate DF, Ries AV, Brown JD, Devellis RF, Ammerman AS: A social media-based physical activity intervention: a randomized controlled trial. Am J Prev Med 2012, 43:527-532.

27. Brindal E, Freyne J, Saunders I, Berkovsky S, Smith G, Noakes M: Features predicting weight loss in overweight or obese participants in a webbased intervention: randomized trial. J Med Internet Res 2012, 14:e173.

28. Foster C, Richards J, Thorogood M, Hillsdon M: Remote and web 2.0 interventions for promoting physical activity. Cochrane Database Syst Rev 2013, Issue 9. Art. no. CD010395.

29. Constine J: Facebook's Q2: Monthly Users Up 21\% YOY To 1.15B, Dailies Up 27\% To 699M, Mobile Monthlies Up 51\% To 819M. Retrieved October 3th, 2013 from http://techcrunch.com/2013/07/24/facebook-growth-2/

30. Korda $\mathrm{H}$, Itani Z: Harnessing social media for health promotion and behavior change. Health Promot Pract 2013, 14:15-23.

31. Crutzen R, De Nooijer J, Brouwer W, Oenema A, Brug J, De Vries NK: Effectiveness of online word of mouth on exposure to an Internet-delivered intervention. Psychol Health 2009, 24(6):651-661.

32. De Bruyn A, Lilien GL: A multi-stage model of word-of-mouth influence through viral marketing. Int J Res Market 2008, 25:151-163.

33. Schein R, Wilson K, Keelan J: Literature review on effectiveness of the use of social media: a report for Peel Public Health. Retrieved October 3rd, 2013 from http://www.peelregion.ca/health/resources/pdf/socialmedia.pdf.

34. Greaves CJ, Sheppard KE, Abraham C, Hardeman W, Roden M, Evans PH, Schwarz $P$ : Systematic review of reviews of intervention components associated with increased effectiveness in dietary and physical activity interventions. BMC Publ Health 2011, 11:119.

35. Smith Anderson-Bill E, Winett RA, Wojcik JR: Social cognitive determinants of nutrition and physical activity among web-health users enrolling in an online intervention: The influence of social support, self-efficacy, outcome expectations, and self-regulation. J Med Internet Res 2011, 13:e28.

36. Eysenbach G: Medicine 2.0: Social networking, collaboration, participation, apomediation, and openness. J Med Internet Res 2008, 10:e22.

37. Michie S, Abraham C, Whittington C, McAteer J, Gupta S: Effective techniques in healthy eating and physical activity interventions: a meta-regression. Health Psychol 2009, 28:690-701.

38. Newell S, Bowman JA, Cockburn JD: Can compliance with nonpharmacological treatments for cardiovascular disease be improved? Prev Med 2000, 18:253-261.

39. Bonnar-Kidd KK, Black DR, Mattson M, Coster D: Online physical activity information: will typical users find quality information? Health Comm 2009, 24:165-175.

40. Shahar S, Shirley N, Noah SA: Quality and accuracy assessment of nutrition information on the Web for cancer prevention. Informat Health Soc Care 2013, 38:15-26.

41. Gorczynski P, Patel H, Ganguli R: Evaluating the accuracy, quality, and readability of online physical activity, exercise, and sport information for people with schizophrenia. Mental Health and Phys Activ 2013, 6:95-99.

42. Whitten P, Smith S, Munday S, LaPlante C: Communication assessment of the most frequented breast cancer websites: evaluation of design and theoretical criteria. J Comp Mediat Comm 2008, 13:880-911.

43. Vandelanotte C: Are simultaneously delivered health behavior change interventions the Way of the future?: A comment on King et al. Ann Beh Med 2013, 46(2):133-134

44. King AC, Castro CM, Buman MP. Hekler EB, Urizar GG Jr, Ahn DK. Behavioral impacts of sequentially versus simultaneously delivered dietary plus physical activity interventions: the CALM trial. Ann Beh Med 2013, 46(2):157-168

45. Spittaels H, De Bourdeaudhuij I, Vandelanotte C: Evaluation of a websitedelivered computer-tailored intervention for increasing physical activity in the general population. Prev Med 2007, 44:209-217.

\section{doi:10.1186/s12966-014-0105-0}

Cite this article as: Vandelanotte et al: Examining the use of evidence-based and social media supported tools in freely accessible physical activity intervention websites. International Journal of Behavioral Nutrition and Physical Activity 2014 11:105.

\section{Submit your next manuscript to BioMed Central and take full advantage of:}

- Convenient online submission

- Thorough peer review

- No space constraints or color figure charges

- Immediate publication on acceptance

- Inclusion in PubMed, CAS, Scopus and Google Scholar

- Research which is freely available for redistribution 